\title{
DIVERSIDADE GENÉTICA E ESTRUTURA POPULACIONAL DE JOHNGARTHIA LAGOSTOMA (H. MILNE EDWARDS, 1837) ESTIMADA POR MARCADORES SSR ESPÉCIE-ESPECÍFICO
}

\author{
Alencar, M.C. ${ }^{1,{ }^{*}}$; Tavares, M.D.S. ${ }^{2}$ \& Faria, F.C.R. ${ }^{1}$ \\ ${ }^{1}$ Universidade de Mogi das Cruzes (UMC), Campus Mogi das Cruzes, \\ Laboratório de Genética de Organismos Aquáticos e Aquicultura (LAGOAA). \\ ${ }^{2}$ Museu de Zoologia da Universidade de São Paulo (MZUSP). \\ *Autor correspondente: mcatarina92@gmail.com, mdst@usp.br, fabiola@umc.br
}

O caranguejo-amarelo Johngarthia lagostoma (H. Milne Edwards, 1837) é endêmico de ilhas oceânicas, sendo encontrado em Atol das Rocas, Arquipélago de Fernando de Noronha, ilhas de Trindade e Martim Vaz e Ascensão ilha britânica no oceano Atlântico Sul. A degradação do habitat, a introdução de espécies invasoras e a biologia da espécie contribuíram para a mesma fosse categorizada como "Em perigo (EN)" pelo ICMBio. Sendo assim, há necessidade de compreender a diversidade e a estrutura genética da espécie em questão, onde atualmente, dentro dos diferentes marcadores moleculares, os microssatélites são os mais utilizados. Diante do exposto, objetivou-se avaliar a estrutura de populações de J. lagostoma utilizando marcadores SSR espécieespecífico, visando explicar a distribuição atual das populações e fornecer subsídios para futuros estudos para a conservação da espécie. O gDNA foi extraído de 13 indivíduos de Fernando de Noronha, 23 de Trindade e 09 de Ascensão que estão depositados na coleção carcinológica no MZUSP. A diversidade genética das populações foi avaliada por meio da amplificação de 13 loci microssatélites espécie-específico. Foi obtido um total de 130 alelos, com média de 13 alelos por loci. O PIC foi alto, variando de 0,69 (JI30) a 0,94 (Jl25) indicando que as populações apresentam uma alta variabilidade genética. Quando analisadas em conjunto as populações de diferentes localidades apresentam a média da heterozigosidade observada, menor que a heterozigosidade esperada, o que corrobora com padrões esperados para populações. O fluxo gênico calculado baseado no método de Slatkin, obteve valores $<1$, demonstrando uma possível diferenciação das populações analisadas. Os valores de Fst indicam pouca diferenciação entre Trindade e Ascensão, e moderada entre Trindade e Fernando de Noronha e Fernando de Noronha e Ascensão. O Fis $(0,532)$ e o Fit $(0,559)$, foram elevados podendo indicar um alto grau de endocruzamento entre indivíduos de uma mesma população. O software Structure indicou K $=4$ e esses resultados sugerem que existem quatro subgrupos genéticos, dois em Trindade, um em Fernando de Noronha e um em Ascensão. Diante do exposto pode se afirmar que a espécie merece status de conservação e pela estrutura genética observada pode se sugerir que, para fins conservacionistas, pelo menos três unidades de manejo devem ser consideradas sendo uma da ilha de Ascensão, uma segunda unidade de Trindade e uma terceira unidade em Fernando de Noronha.

Palavras-chave: conservação, Gecarcinidae, genética de população, marcadores microssatélites. 